\title{
Prevalence And Predictors Of Mental Health Problems Among An Elderly Population Of Pakistan
}

\author{
Aaqib Shahzad Alvi \\ Department of Social Work \\ University of Sargodha \\ Sarah Safdar \\ Faculty of Management and Social Sciences \\ Iqra National University
}

\begin{abstract}
The aim of the present study was to explore the prevalence and predictors of mental health problems among elderly. Self Reporting Questionnaire (SRQ20) was used as tool of data collection from 624 elderly aged 60+ using multistage sampling technique. Logistic regression analysis was performed to identify factors associated with mental health problems. Results indicated a pervasive prevalence of mental health problems among elderly in Central Punjab. Logistic regression analysis reported that various independent factors, including financial dependency, educational status, undesirable events of life, undermining the sense of control, elderly abuse, feelings of discomfort at home, behavior of family, age and gender of elderly were significantly linked with mental health problems of Pakistani elderly population. These notably linked variables were instigated as the major risk factors of mental health problems. These findings also pointed out that the respondents who were monetarily dependent and did not have any source for familial support were two times more likely to report mental health problems than those who had finances. It means that the financial dependency dominates other risk factors.

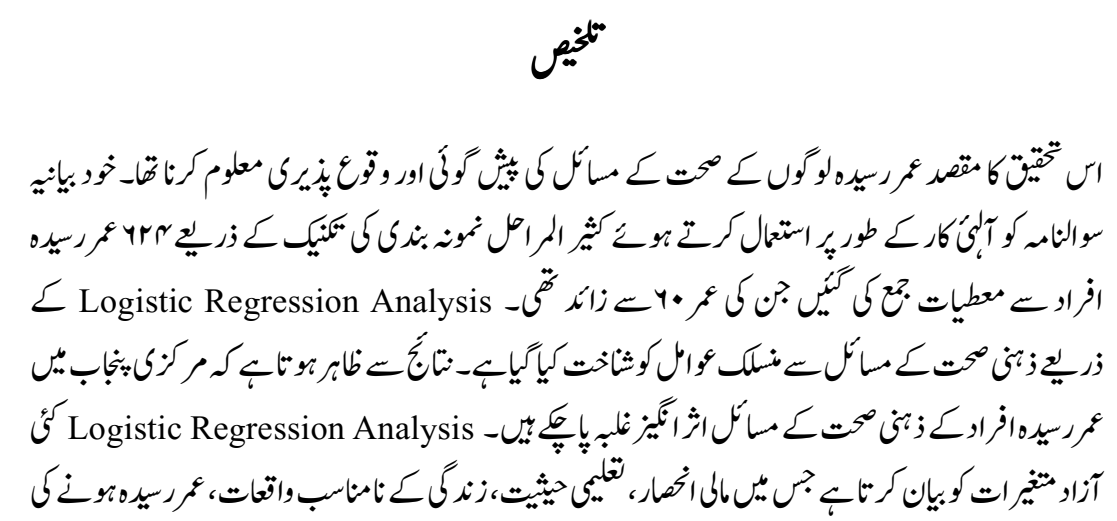




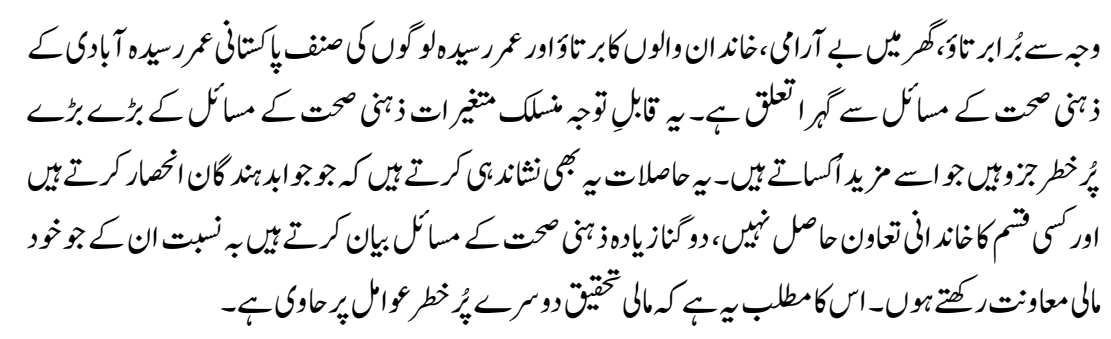

\section{Introduction}

The World Health Organization pointed out, twenty five percent of the world's population suffered from mental health problems (WHO, 2001 cited in National Plan Action-NCDS-Pakistan, 2004). The planning commission survey indicated that ten million populace were recognized as mildly ill and one million were lying in the category of severe illness in Pakistan (National Plan Action-Pakistan, 2004). This research looks at the occurrence and correlation of mental health problems among elderly in Punjab, larger province of Pakistan comprising of immense population of elderly."The mental health problems denote emotional and psychological difficulties, which cause distress and interfere with how people go about their everyday lives" (European Commission Report, 2008).

Keeping in view the previous studies it was concluded that mental health problems (MHPs) had an extensive range. The thinking, feelings and body of older persons have been destroyed by the mental health problems. The range of these problems was too large that they begin from daily life cares and worries and advanced to harsh conditions. Depression, bipolar disorder (manic depressive illness), attention deficit (hyper activity disorder), anxiety, eating disorders, schizophrenia, dementia, alziemer, and conduct disorders were categorized in mental health problems (Chopra, 2005). Neuroses, often conveyed as 'common mental health problems', including depression and anxiety that might be a source of suffering and had impact on daily life but did not add perceptional problems i.e. Hallucination or hearing voices (Karban, 2011). In this study the researcher dealt with the problems of daily life and 'Neuroses' were taken as 'Mental Health Problems'.

The recent figure of Pakistani elderly population touches the figure of 11.5 million in Pakistan. This population will increase to sixteen million in 2020 and will be fifty million in 2050. In recent times, the 60 and above older persons comprised of $6 \%$ of the national population of country (UNDESA, 2009). The 
populace of female elderly is going to increase as compared to male due to raising life expectancy of female elderly (Khalid, 2003).

Abundant studies have been carried out in developed countries (Chow et al., 2004) to gauge the pervasiveness and risk factors of depression among the senior citizens whereas a few sizeable studies have been made in developing world (AlShammari \& Al-Subaie, 1999; \& Thongtang et al., 2002). The prevalence rate and risk factors/predictors varies depending upon the origin of country and study setting. The percentage of prevalence of mental health problems varied from 0.9 $\%$ to $42 \%$ (Djernes, 2006). The occurance of mental health problems was estimated more than cancer and cardiac diseases (Substance Abuse and Mental Health Services Administration, SAMSHA). Several studies have been launched in Pakistan regarding the need \& problems and socio-economic condition of elderly but a little work has been done in mental health domain of elderly.

A study indicated that a minute percentage of senior citizens were having excellent health status and almost one forth had poor health status (Hafeez, 2004). Alzheimer's disease (16\%) and Parkinson's disease (7.7 \%) have been labeled as mental health problems and it is also reported that the onset of chronic conditions initiated in fifty years of age in Pakistan and developing countries as well. In addition, it was also indicated that one third elderly were suffering from mental health problems in community settings whom needed interventions for treatment (Nour, \& Hebert, 2010). According to the survey carried out in three big cities of Pakistan (Lahore, Quetta, and Karachi) the prevalence of depression was estimated to be $53.4 \%, 43.9 \%$ and $35.7 \%$ respectively (Gadit \& Mugford, 2007). One more study revealed that $43 \%$ community dwellers in a village of Sindh, Pakistan were diagnosed depression and anxiety symptoms (Luni, et al., 2009).

Different factors have been recognized as risk factors of depression in old age. Amongst socio-economic indicators, gender is reported to be notably associated with depressive symptoms (Barry et al., 2008). Depression among 60+ women was found more than older men (Beekman et al., 1999; Bracken \& Reintjes 2009; \& Heikkinen \& Kauppinen 2004). Several causes have been recommended to describe this variation, such as selective survival. For instance, older male depart their life earlier and mortality may be affected by genetic factors (Yi et al., 2003).

The survey about the problems and prospects of $60+$ generation revealed that the vulnerability of elderly was directly associated with the failure of family support 
and this vulnerability became double in case of too poor families (The Situation of Elderly Population in Pakistan: Problems and Prospects, 2008). The same result was produced in a survey conducted in Punjab, level of satisfaction of elderly was considerably attached with those who did not have any conflicting situation within family set up (Nizamuddin \& Maqsood, 2010).

The loss of roles and status, decision making, lack of social networking, snatches of rights, poverty, retirement, widowhood, dependency, unmet social and emotional needs, disability, sickness, ageing, launching of children and institutionalization were social forces that might cause the distortion of mental health among older persons. This state of affairs diminished their hope for life and they became the victims of mental health problems such as depression, anxiety, stress, and dementia (Atchley, 1988). Dependency, female sex, illiteracy, financial difficulties, being a housewife and problems in family relations were reported the major causes that lead aged persons towards threshold of vulnerability (Mirza \& Jenkins, 2004).

Mental health problems were negatively associated with socio-economic status and people with low socio-economic status were found to be more depressed (Dar, 1996; Gresenz et al., 2001; \& Muramatsu, 2003). They have to face stressful events in life and they have few resources to cope with these causes of stress more effectively (Aneshensel, 1992; \& Kessler \& Cleary, 1979). Psychological distress across the life was positively associated with economic strain (Angel et al., 2003; Krause, 1997; Miech \& Shanahan, 2000; \& Mirowsky \& Ross, 2001).

Little information is accessible in the mental health domain among elderly of Pakistan. Therefore, a need was felt to assess the pervasiveness of mental health problems and gauged their determinants in geriatric populace of Pakistan. It might identify various interventions and further researchers in this particular dimension.

\section{Methods}

This study was carried out in the central Punjab. Punjab comprised of three zones i.e. Southern Punjab, Central Punjab, and Northern Punjab (Nizamuddin, et al., 2010). The central zone was chosen by the researcher due to its diversity in changing life styles \& family structure, cultural diffusion, modernization, mass media, urbanization and geographical proximity was considered as well. 
The sample size was 624 elderly. $6 \%$ population of the $60+$ senior citizens was taken from the inhabitants of the Central Punjab i.e. 2921280 (Census Bureau of Pakistan, 1998) which was the human universe to take sample. The sample size was taken by using the formula $\mathrm{N} / 1+\mathrm{Ne}^{2}$ given by Taro Yamane (Yamane, 1967: p. 95). Male and female ( $60 \&$ above) were interviewed dwelling in community.

Multistage sampling method was applied to draw a sample. Central Punjab comprised of 16 districts. At first step, one-fourth of the districts from Central Punjab were picked by applying simple random sampling technique. The simple random is a type of probability sampling, in which each item has equal chance to be selected (Browne, 2002). At the second phase, one tehsil from each already chosen district was selected through simple random sampling. Thirdly, urban and rural blocks/strata were selected out of tehsils. The rural and urban areas had been divided into blocks having 250 households. At the fourth phase the total sample was confirmed by applying the formula i.e.

$$
\text { Sample }=\frac{\text { Total Blocks of Selected Tehsils }}{\text { Total Blocks of all Tehsils }} * \text { Required Sample }
$$

At final stage, the elderly were approached by using convenience sampling technique. Equal representation was given to both rural and urban community. Interview schedule (developed by the researcher) and Self Reported Questionnaire (SRQ-20) (developed by WHO) were administered for data collection. Interview schedule comprised of four parts i.e. socio-economic profile, family behaviour, risk factors of mental health problems and coping strategies among elderly. The Self Reporting questionnaire has been used to assess the psychological distress and mental health problem in different community as well as psychiatric settings (Ventevogel, 2007). It was applied by WHO in many countries of Third World where the mental health services are not satisfactory (WHO Division of Mental Health, 1994). SRQ-20 had been used to estimate the mental health problems of aged population in Central Punjab. It comprises of twenty items/questions. It has neurotic items only, reflecting depressive symptoms, anxiety and psychosomatic complaints. In case of illiterate respondents, SRQ-20 might be used as interviewer administered questionnaire (Scholte, et al. 2011). A cut off score has been used 7 to 8 in several studies and same cut off used in the current study (Scholte, et al. 2011). Data was entered on SPSS-16 version. The T- Test and multiple Logistic Regression were used to estimate the factors correlated with mental health problems. 


\section{Results}

The average age of respondent was 73 years. Majority was illiterate and the rest of them had primary level education. Almost half of the elderly belong to uneducated family set up. $51.8 \%$ were residing in joint family system while one third was living within nuclear family system. The average family size of elderly was eight family members. $72.7 \%$ of respondents were married and less than one forth was widows.

While discussing the working situation of respondents, it was indicated that half of the aged women did not have any job or monetary source, as in Pakistani culture majority of women were living as housewives. Half of the male elderly have their own independent source of income and rest of them was dependent on their offspring. The average family income and respondents' income was Rs. 19,793 and Rs. 10,289 respectively. The respondents who did not work reported that they stopped work due to health disturbance and retirement.

A gradual decrease in level of respect was observed with the increase in age. $68 \%$ elderly reported that they were enjoying a respectable status in family when they were young but in the old age they perceived reduction in level of respect. $62.5 \%$ replied positively regarding the acceptance of opinion in daily life routine activities. $60.9 \%$ respondents reported that they were satisfied with the behaviour of family members and remaining almost one third was not satisfied.

A high percentage of prevalence of mental health problems was estimated i.e. 42 $\%$ of older persons were suffering from mental health problems. Gender wise difference was observed; female elderly estimated more symptoms of mental health problems in comparison with males. An independent-sample T-test was applied to gauge percentage of mental health problems (applying Self Reporting Questionnaire SRQ-20) for equal number of male elderly and female elderly. 0.000 significant level was estimated, supporting the hypothesis that female elderly have higher level of mental health problems than male elderly.

The binary logistic regression analysis was used to estimate association between predictors (independent variables) and mental health problems. The model restrains the nine independent variables (financial dependency, education of respondents, undesirable events of life, undermining the sense of control, elderly abuse, and feelings of discomfort at home, accommodation change, and behavior 
of family and age of respondents). Regression analysis indicated that eight factors were associated with mental health problems whereas change of accommodated was slightly associated. These factors were categorized as risk factors/causes of mental health problems. The economic dependency was reported as a strongest predictor among risk factors of mental health problems. It means that the financial dependency was the major risk factor that played an important role in the disruption of mental health among elderly.

Table - Binary Logistic Regression Analysis of Factors Associated with Mental Health Problems among Elderly Population of Punjab, Pakistan

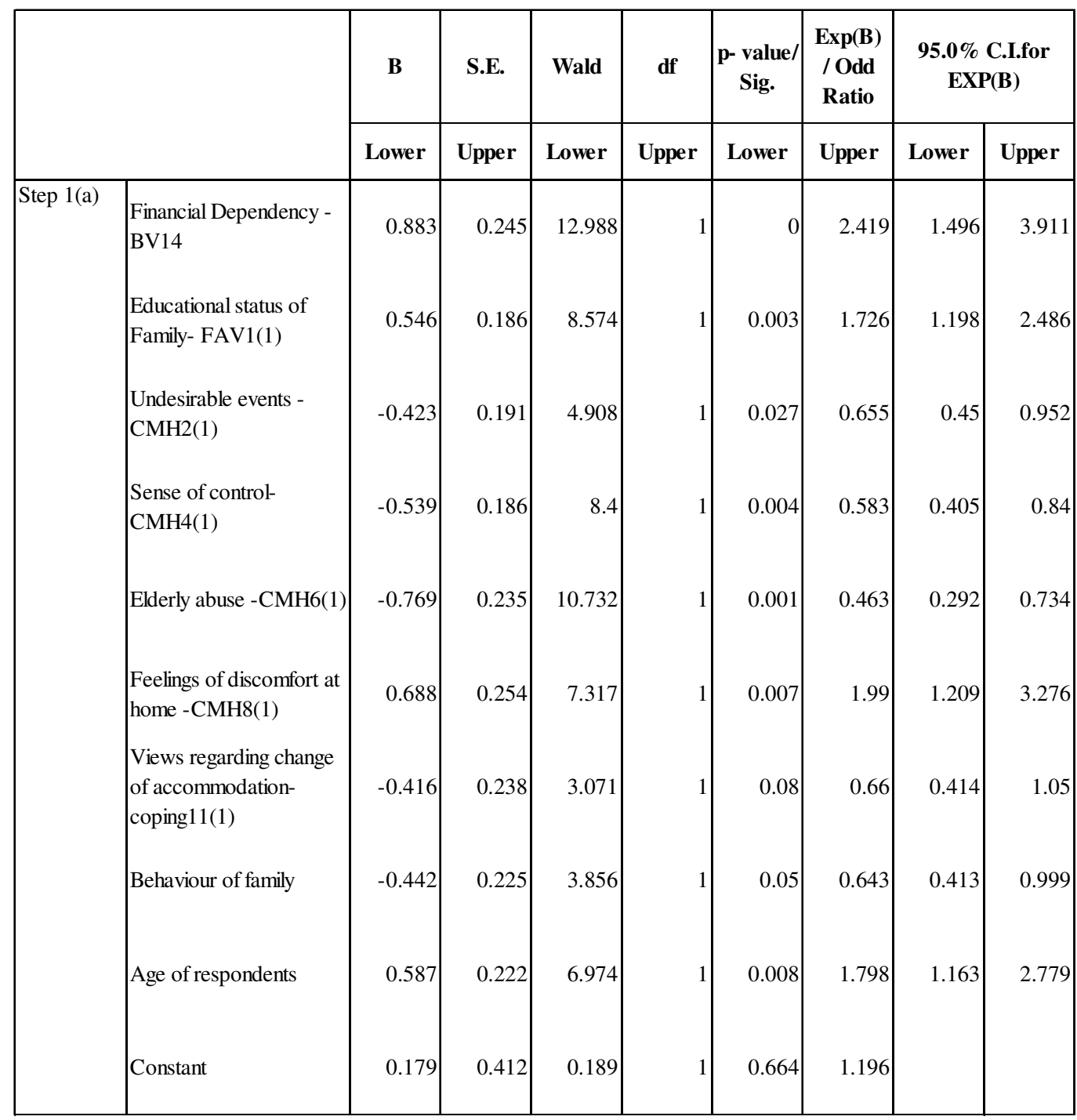


In case of elderly abuse, $5 \%$ elderly was facing physical abuse and $19 \%$ were encountered with the psychological abuse. $21.5 \%$ respondents reported feelings of discomfort at home and this discomfort was due to family misbehaviour and economic problems. Moreover, undesirable events of life was estimated as a risk factor of MHPs. In this case almost one third older persons faced undesirable events in life, including death of loved ones and loss of business. Similarly, Age factor, undermining sense of control and family behaviour were recognized as the prominent factors to affect the mental health.

\section{Discussion}

The pervasiveness of mental health problems among older persons were examined highly significant. These results of study are in line with the study conducted by Harpham and his fellow researchers (2004). They revealed high percentage of mental health problems range from $18 \%$ to $42 \%$ by applying the SRQ-20 in the community. In addition, the results of studies carried out at indigenous level indicated variation regarding the prevalence of mental health problems from $10 \%$ to $66 \%$ (Ganatra, Zafar, Qidwai, \& Rozi, 2008; Hussain, Cree \& Thomenson, 2000; Luni, Ansari, Jawad, Dawson, \& Baig, 2009; Mirza \& Jenkins, 2004; Mumford, Minhas, Akhtar, \& Mubbashar, 1997; \& Mumford, Minhas, Akhtar, \& Mubbashar, 2000).

Studies of western countries indicated low percentage of mental health problems in community rather than institutional setting. Contrary to these findings of west, the pervasiveness of mental health problems were estimated high in community settings as well. The possible explanation of this finding could be that in our society a large number of community dwellers were living below poverty line (Qureshi, sarfaraz \& Arif , 2001) and $33 \%$ Pakistani populace has been estimated that they were living below poverty line and previous studies supported the results that mental illness increased with the increase in poverty (Skapinakis, 2006 \& Willenz, 2005). They have plenty of difficulties in the fulfillment of basic necessities of life, for instance the research work of Willenz (2005) showed that a bulk of Pakistanis did not have access to the proper medical treatment and health provisions. Moreover findings of previous studies also document that economic stress directed to psychological distress (Gresenz et al., 2001; Miech \& Shanahan 2000; Mirowsky \& Ross 2001; \& Muramatsu 2003). 
The gender wise variation has been observed in the current study. The women were facing more mental health problem symptoms as compared to male elderly. The present study confirmed the findings of the prior studies in Pakistan and other countries that the occurrence of depression was greater among older women rather than older men (Barry et al., 2008; Hussain, Chaudhry, Afridi, Thomenson, \& Creed, 2007; Mumford, Nazir, Jilani, \& Baig, 1996; \& Luni, et al., 2009). One prominent reason of this variation lies within the issues of survivability that is higher in female elderly.

In addition, two other factors also support this fact, males are egoistic and they try to keep secret their cares and worries of life but women are more expressive. In this study, the researcher observed this phenomenon during data collection. The second important factor is that the men are habitual to have good relationships with their fellows and like social networking and they move outside in community. But in our eastern culture women have to confine within four walls of household setting and they are dependent on men in many routine matter affairs of life. These results are in line with the study of Ahmed (2011) reported that social networking and social support were positively associated with improvement of quality of life of elderly. Moreover, they have to live alone at home and living alone was also correlated with a three to six fold increase in the risk of depressive symptoms (Lee \& DeMaris, 2007).

Regression analysis indicated that eight variables had positive association with mental health problems. These factors were categorized as risk factors/causes of mental health problems. The economic dependency was recognized as a strongest predictor (independent variable) among risk factor of mental health problems. It indicates that the financial dependency was the major risk factor that had adverse impact on mental health of older persons. These results are validated in the previous studies that lack of education, poverty, family misbehave were linked with the mental health problems and these factors were recognized as the risk factors. Abundant of risk factors among geriatric depression have been reported in prior literature such as low literacy levels, poor vision, swallowing difficulties, financial dependency, discomfort in life, poor health, bereavement, sleeplessness, memory impairment, depression, female gender, conflict among family members, physical diseases, use of medication, dependency in routine life activities, unemployment, divorced or widowed status, isolation and urinary incontinence (Chow et al., 2004; Cole \& Dendukuri, 2003; Garcia Serrano \& Tobias Ferrer, 2001; Heun \& Hein, 2005; Maqsood et, al., 2013; Mirza \& Jenkins, 2004; 
MSWWS, Govt. of Pakistan, 2000; kaneko, Mothohashi, Sasaki, \& Yamaji, 2007; \& Thongtang et al., 2002).

Taqui et al., (2007) also found that jobless or retired elderly had two times more percentage of depression than those who have any source of income. In relation to lack of economic dependency as risk factors, Abas and Broadhead (1997) found a noteworthy association with formal employment, below average income. The same results also concluded in many previous studies (Bae, Kim, \& Yoon, 2005; Jeon, 2007; \& Stankunas , Kalediene, Starkuviene, \& Kapustinskiene, 2006).

\section{Conclusions}

The prevalence of mental health problems among elderly estimated in this study was high than that of many other countries. Therefore, efforts should be made to control this alarming increase. There are recently 11 million 60+ older populace in Pakistan and this study revealed high prevalence of mental health problems. We might manage this high percentage to identify many easily changeable risk factors of mental health problems among elderly.

Therefore, through the joint efforts of health care department, social welfare department, government and non-governmental sector working in the field of senior citizens, an improvement in the geriatric health especially in the domain of mental health is achievable. Moreover, more sizeable studies should be carried out to precisely estimate the pervasiveness of mental health problems in different communities and made comprehensive plan of action to address these geriatric mental health issues.

\section{References}

Abas, M. \& Broadhead, J. (1997). Depression and Anxiety among Women in an Urban Setting in Zimbabwe, Psychol Med, vol. 27, No. (1) pp. 59-71.

Ahmed, K. \& Hafeez, M. (2011). Factors Affecting Social Participation of Elderly People: A Study in Lahore, The Journal of Animal and Plant Sciences, vol. 21(2), pp. 283-289. 
Al-Shammari, S. A. \& Al-Subaie, A. (1999). Prevalence and Correlates of Depression among Saudi Elderly, International Journal of Geriatric Psychiatry, vol. 14(9), pp. 739-747.

Aneshensel, C. S. (1992). Social Stress: Theory and Research, Annual Review of Sociology, pp. 18, 15-38.

Angel, R. J., Frisco, M., Angel, J. L. \& Chiriborga, D. A. (2003). Financial Strain and Health among Elderly Mexican-Origin individuals, Journal of Health and Social Behaviour, vol. 44, pp. 536-551.

Atchley, C. R. (1988). Social Forces and Ageing, Californai: Wadsworth Publishing Company.

Bae, J. Y., Kim, W. H., \& Yoon, K. A. (2005). Noinui uul mit Jasal Senggake Yiseoseo Saheoigeock Jijiui Wanchung Hyogwua Depression, Suicidal Thoughts and the Buffering Effect of Social Support among the Elderly, Journal of the Korean Gerontological Society, vol. 25, pp. 59-73.

Barry, L. C., Allore, H. G., Guo, Z., Bruce, M. L., \& Gill, T. M. (2008). Higher Burden of Depression among Older Women: The Effect of Onset, Persistence, and Mortality Over Time, Archives of General Psychiatry, vol. 65(2), pp. 172-178.

Beekman, A. T., Copeland, J. R., \& Prince, M. J. (1999). Review of Community Prevalence of Depression in Later Life, The British Journal of Psychiatry, vol. 174, pp. 307-311.

Bracken, B. A., \& Reintjes, C. (2009). Age, Race, and Gender Differences in Depressive Symptoms: A Lifespan Developmental Investigation, Journal of Psycho Educational Assessment, vol. 28(1), pp. 40-53.

Browne, K. (2002). Introducing Sociology For AS Level. Cambrigde: Polity Press.

Census Bureau of Pakistan, (1998). http://www.pbs.gov.pk/content/ population-census 
Chopra, (2005). Health Problems: A Community Collaboration, Journal of the Centre de Research et Expertise En Gerentologie Sociale, vol. 1, pp. 15-23.

Chow, E. S. Kong, B. M., Wrong, M. ., Draper, B., Lin, K. L., Ho, S. K., \& et al. (2004). The Prevalence of Depressive Symptoms among Elderly Chinese Private Nursing Home Residents in Hong Kong, International Journal of Geriatric Psychiatry, vol. 19(8), pp. 734-740.

Cole, M. \& Dendukuri, N. (2003). Risk Factors for Depression among Elderly Community Subjects: A Systematic Review and Meta-Analysis, American Journal of Psychiatry, vol. 160(6), pp. 1147-1156.

Dar, R. H. (1996). Status of the aged in Modernizing Society, Department of Sociology, University of the Punjab, Lahore: Pakistan.

Djernes, J.K. (2006). Prevalence and Predictors of Depression in Populations of Elderly: A Review. Acta Psychiatrica Scandinavica, vol. 113(5), pp. 372-387.

European Commission. (2008). Mental Health in EU Key Facts, Figures and Activities, A Back Ground Paper Provided by the Support Project, 2008. Luxembourg.

Gadit, A. A. \& Mugford, G. (2007). Prevalence of Depression among Households in Three Capital Cities of Pakistan: Need to Revise the Mental Health Policy, PLOS ONE, vol. 2(2), pp. 209-215. doi:10.1371/journal.pone.0000209

Ganatra, H., Zafar, S., Qidwai, W. \& Rozi, S. (2008). Prevalence and Predictors of Depression among an Elderly Population of Pakistan, Ageing \& Mental Health, vol. 12(3), pp. 349-356.

Garcia Serrano, M. J. \& Tobias, F. J. (2001). Prevalence of Depression in Patients Over 65 Years of Age, Profile of the Elderly at Risk, Atencion Primaria, vol. 27(7), pp. 484-488.

Gresenz, C. R., Sturm, R. \& Tang, L. (2001). Income and Mental Health: Unravelling Community and Individual Level Relationships, The Journal of Mental Health Policy and Economics, vol. 4(4), pp. 197-203. 
Gresenz, C. R., Sturm, R. \& Tang, L. (2001). Income and Mental Health: Unravelling Community and Individual Level Relationships, The Journal of Mental Health Policy and Economics, vol. 4(4), pp. 197-203.

Hafeez, M. (2004). Ageing and Family: Perceived Life Situation of an Elderly Population in Pakistan: Gender Based Finding from Urban, Lahore, Sharing Population and Development Research across South and West Asia, Presented at the Fifth Annual Research Conference Proceedings 1416, Lahore: Population Association Pakistan, pp. 365-385.

Harphom, T., Reichenheim, M., Oser, R., Thomas, E., Hamid, E., Jaswal, S., \& et al. (2003). How to do (or not to do) Measuring Mental Health in a CostEffective Manner, Health Policy and Planning, vol. 18(3), pp. 344-349.

Heath, John M. et al. (2005). The Prevalence of Undiagnosed Geriatric Health Conditions Among Adult Protective Service Clients, The Gerontologist, vol. 45(6), pp. 820-823.

Heath, J.M., Brown, M., Kobylarz, F.A., \& Castano, S. (2005). The Prevalence of Undiagnosed Geriatric Health.

Heikkinen, R. L., \& Kauppinen, M. (2004). Depressive Symptoms in Late Life: A 10-year Follow-up, Archives of Gerontology and Geriatrics, vol. 38(3), pp. 239-250.

Heun, R., \& Hein, S. (2005). Risk Factors of Major Depression in the Elderly, European Psychiatry, European Psychiatry, vol. 20(3), pp. 199-204.

Hussain, N., Chaudry, I. B., Afridi, M. A., Thomenson, B., \& Creed, F. (2007). Life Stress and Depression in a Tribal Area of Pakistan, British Journal of Psychiatry, vol. 190, pp. 36-41.

Hussain, N., Creed, F., \& Thomenson, B. (2000). Depression and Social Distress in Pakistan, Psychological Medicine, 30, pp. 395-402.

Jeon, J., Jang, S. N., Rhee, S. J., Kawachi, I., \& Cho, S. (2007). Gender differences in correlates of mental health among elderly Koreans, Journal of Gerontology: SOCIAL SCIENCES, 62 B(5), pp. 323-329. 
Kaneko, Y., Motohashi, Y., Sasaki, H., \& Yamaji, M. (2007). Prevalence of depressive symptoms and related risk factors for depressive symptoms among elderly persons living in a rural Japanese community: a crosssectional study. Community Mental Health Journal, 43(6), pp. 583-589.

Karban, K. (2011). Social Work and Mental Health. USA: Polity Press.

Kessler, R. C. (1979). A strategy for studying differential vulnerability to the psychological consequences of stress. Journal of Health and Social Behavior, vol. 20, pp. 100-108.

Khalid, M. (2003). Social Problems of Pakistan. Karachi: Kifayat Academy.

Krause, N. (1997). Anticipated support, received support and economic stress among older adults, Journals of Gerontology: Psychological Sciences, vol. 52, pp. 284-293.

Lee, G. R., \& DeMaris, A. (2007). Widowhood, gender, and depression: A longitudinal analysis, Research on Aging.

Luni, F. K., Ansari, B., Jawad, A., Dawson, A., \& Baig, S. . (2009). Prevalence of depression and anxiety in a village in Sindh. Journal of Ayub Medical College Abbottabad, 2l(2). http://www.ayubmed.edu.pk/JAMC/70 PAST/21-2/Faraz.pdf.

Maqsood, F., Flatt, D. Albert, S. Maqsood, S. \& Nizamuddin, M. (2013). Correlates of self-reported depressive symptoms: a study of older persons of punjab, Pakistan. J Cross Cult Gerontol, vol. 28, pp. 65-74.

Miech, R. A. \& Shanahan, M. J. (2000). Socioeconomic status and depression over the life course. Journal of Health and Social Behavior, vol. 41, pp. $162-176$.

Mills, T. L. \& Henretta, J. C. (2001). Racial, ethnic, and sociodemographic differences in the level of psychosocial distress among older Americans, Research on Aging, 23(2). Pp. 131-152. 
Mirowsky, J. \& Ross, C. E. (2001). Age and the effect of economic hardship on depression, Journal of Health and Social Behavior, vol. 42(2). pp. 132150.

Mirza, I. \& Jenkins, R. (2004b). Risk factors, prevalence, and treatment of anxiety and depressive disorders in Pakistan: systematic review. British Medical Journal. doi:10.1136/bmj.328.7443.794

Mumford BD, Minhas, F. A., Akhtar, I., Akhtar, S. \& Mubashar, M. (2000). Stress and Psychiatric Disorder in Urban Rawalpindi, Community survey, British Journal of Psychiatry, vol. 177, pp. 557-562. doi:10.3109/ 09540269309028307

Mumford BD, Nazir, M., Jilani, F. U. \& Baig, I. Y. (1996). Stress and psychiatric disorder in the Hindu Kush: a community survey of mountain villages in Chitral, Pakistan. British Journal of Psychiatry, vol. 68, pp. 299-307.

Mumford BD, Saeed, K., Ahmed, I., Latif, S. \& Mubashar, M. H. (1997). Stress and psychiatric disorder in rural Punjab. A community survey. British Journal of Psychiatry, vol. 170, pp. 473-478.

Muramatsu, N. (2003). County- level income inequality and depression among older Americans, Health Service Research, vol. 38, pp. 1863-1884.

National Plan of Action, (2004). http://planipolis.iiep.unesco.org/upload/Pakistan/ Pakistan\%20EFA\%20roadmap.pdf

Nizamuddin, M., Maqsood, F. \& Ahmed, J. S. (2010). How the Elderly Live in Punjab-A Field Survey of the Living Conditions and Health Status of the Elderly of Punjab 2009, University of Gujrat, Pakistan.

Nour, K. \& Herbert, M. (2010). Older Adults with mental Chopra, 2005 Health Problems; A Community Collaboration, Journal of the Centre de Researche et Expertise En Gerentologie Sociale, vol. 1, pp. 15-23.

Pakistan Institute of Development Economics, Islamabad (MIMAP Technical Paper Series No. 5. 
Qureshi, Sarfraz K. \& Arif, G. M. (2001). Profile of Poverty in Pakistan, 1998-99.

Scholte, W. ., Verduin, F., Lammeren, A. V., Rutayisire, T., \& Kamperman, A. M. (2011). Psychometric properties and longitudinal validation of the self reporting questionnaire (SRQ-20) in a Rawandan community setting: a validation study. Medical Research Methodology, 11. http// www. Biomedcentral.com/1471/11/116

Skapinakis, P. (2006). Socio-economic positions and common mental disorders: longitudinal study in the general population in uk, The British journal of Psychiatry, vol. 189(2). pp. 109-117.

Stankunas, M., Kalediene, R., Starkuviene, S. \& Kapustinskiene, V. (2006). Duration of unemployment and depression: a cross-sectional survey in Lithuania. BMC Public Health, 6, 174-79. doi:10.1186/1471-2458-6-174.

Substance Abuse and Mental Health Services Administration (SAMSHA). Retrieved December 6, 2014, from http:// www.samhsa.gov.

Taqui, A. ., Itrat, A., Qidwai, W., \& Qadri, Z. (2007). Depression in the elderly: Does family play a role? A Cross-sectional Study, BMC Psychiatry, 7, 5762, Thailand, vol. 85(5), pp. 540-544.

The Situation of Elderly Population in Pakistan: Problems and Prospects. (2008). Retrieved January 12, 2012, from http://www.specialsedu.com/2011/01/ situation-of-elderly-population-in.html.

Thongtang, O., Sukhatunga, K., Ngamthipwatthana, T., Chulakadabba, S., Vuthiganond, S., Pooviboonsuk, P., et al. (2002). Prevalence and incidence of depression in the Thai elderly, Journal of the Medical Association of

United Nation Department of Economics and Social Affairs. (2009). World Population Prospects: The 2008 Revision, United Nations, New York. 
Ventevogel, P., Devries, G., Scholte, W. F., Rasa, S. N., Faiz, H., Nassery, R., \& et al. (2007). Properties of the Hopkins symptoms checklist 25 (HSCL-25) and the self reporting questionnaire (SRQ-20) as screening instrument used in primary care in Afghanistan. SOC Psychiatry Psychiatric Epidemiol, vol. 42, pp. 328-335.

Wada, T., Ishine, M., Sakagami, T., Okumiya, K., Fujisawa, M., Murakami, S. (2004). Depression in Japanese community-dwelling elderly-prevalence and association with ADL and QOL. Archives of Gerontology and Geriatrics, vol. 39(1). pp. 15-23.

Willenz, P. (2005). Low socio-economic status in a risk factor for mental illness. Retrieved April 24, 2009, from http:// www.Eurekalert.org/pub_release/ 2005-03/apa-Iss030205.php

World Health Organization. (2001). The World Health Report: Mental Health.

World Health Organization. (2004).National Action Plan for Prevention and Control of Non-Communicable Diseases and Health Promotion in Pakistan.

Yamane, T. (1967). Elementry Sampling Theory. New Jersey: Prentice Hall.

Yi, Z., Yuzhi, L., \& George, L. K. (2003). Gender Differentials of the oldest old in China, Research on Aging, 25, 65-80.

Aaqib Shahzad Alvi is Lecturer in the Department of Social Work, University of Sargodha.

Prof. Dr. Sarah Safdar is Dean, Faculty of Management and Social Sciences, Iqra National University, Peshawar, Pakistan. 